\title{
A construção de um modelo de gestão que promove 0 desenvolvimento sustentável
}

\author{
Carlos Alberto Cioce Sampaio*
}

\section{Resumo}

Diante da dificuldade de encontrar soluções para os problemas elaborados - partindo das metodologias de planejamento - e visando garantir a implantação de tais soluções, surgiu o interesse de propor uma alternativa para superá-los. Para fundamentar essa proposição, foram aprofundados quatro elementos teóricos - gestão organizacional, espaço local, arranjo institucional e dimensões de sustentabilidade. A partir da análise de experiências empíricas pelo prisma desses elementos, foi consolidado um modelo de gestão organizacional estratégica para o desenvolvimento sustentável, resumidamente chamado de SiGOS, cuja maior contribuição consiste em relacionar três importantes ações: a política, a técnica e a ética. A ação política incorpora a diversidade de interesses organizacionais no processo de tomada de decisão. A ação técnica possibilita o equacionamento de três vetores: eficiência de processos, eficácia de resultados e efetividade para os beneficiários. A ação ética está contida numa nova visão paradigmática - que aqui se privilegia -, e que explica a maior parte dos fenômenos observados, permitindo soluções para os problemas que a maioria das pessoas quer resolver; ou seja, tem como objetivo um desenvolvimento socialmente mais justo, ambientalmente prudente e, ainda, economicamente eficiente.

Palavras-chave: gestão organizacional estratégica, planejamento para o desenvolvimento sustentável.

\begin{abstract}
The main purpose of this article is to offer a methodological alternative to overcome the practical difficulties in identifying and implementing solutions to the problems of local development. In order to substantiate the alternative proposed, four theoretical concepts were studied in depth: organizational management, local space, institutional arrangement and sustainable dimensions.
\end{abstract}

Key words: strategic organizational management, sustainable development planning.

\section{Introdução}

Ao longo dos anos de estudo sobre planejamento organizacional, planejamento que promove o desenvolvimento local ou microrregional e planejamento para o desenvolvimento sustentável, verificou-se na prática que os enfoques de planejamento possuem dois pontos comuns importantes para este estudo.

O primeiro ponto é que o planejamento pode ser dividido em três etapas: elaboração, implantação e avaliação. De um modo geral, a etapa de elaboração é aquela que aponta os problemas mais importantes (questões estratégicas), enquanto que a etapa de implantação é a que soluciona os problemas. Já a etapa de avaliação é a que tenta garantir que as medidas para a solução dos problemas sejam de fato implantadas.

O segundo ponto se relaciona com essas três etapas do planejamento: os problemas não são difíceis de serem elaborados, as soluções dos problemas não são fáceis de serem encontradas, e é muito difícil garantir que as soluções dos problemas sejam de fato implantadas.

Diante desses graus de dificuldade nas etapas de implantação e avaliação do planejamento - ou seja, de identificação das soluções dos problemas e implantação dessas soluções -, surgiu o interesse de propor uma alternativa para superação das dificuldades. Para fundamentar essa proposição, foram aprofundados quatro

* Professor da Universidade Regional de Blumenau (FURB). E-mail : sampaio@ furb.com.br.

Artigo recebido em dezembro de 2003 e aceito em fevereiro de 2004. 
elementos teóricos, surgidos do entrelaçamento de dois grandes temas: gestão organizacional estratégica e planejamento para o desenvolvimento sustentável.

O primeiro elemento é a gestão organizacional, originada da etapa de implantação do planejamento, conforme a teoria da administração. O segundo e terceiro elementos, arranjo institucional e espaço local, são conceitos adjacentes construídos (aqui) a partir da teoria do planejamento do desenvolvimento sustentável, a qual, por sua vez, subsidia o quarto elemento que são as dimensões de sustentabilidade.

A relação desses elementos conceituais fundamentou a proposta de um modelo de gestão organizacional estratégica, resumidamente chamado de SiGOS.

\section{Gestão organizacional estratégica}

O modelo SiGOS começou a ser construído a partir da teoria da administração que fornece uma diversidade de metodologias de gestão organizacional. O estudo, porém, limitou-se às metodologias de gestão organizacional, enfocando a relação organização e meio ambiente, denominada gestão organizacional estratégica. Entre essas metodologias foram abordados o planejamento estratégico, a administração estratégica e o pensamento estratégico. Segundo Sampaio (1999), esses enfoques se distinguem pelo tratamento dado ao pensamento e à ação: o planejamento estratégico prima pelo pensamento sobre a ação, a administração estratégica prima pela ação sobre o pensamento, e o pensamento estratégico integra pensamento e ação.

A gestão organizacional estratégica, prossegue Sampaio, está dividida em duas ações técnicas: ação intra-organizacional e ação extra-organizacional. A ação intra-organizacional trata dos critérios internos da organização (eficiência de processos e eficácia de resultados). A ação extra-organizacional lida com os critérios externos da organização (efetividade para os beneficiados).

Sampaio (1999) observa que considerada a complexidade da gestão organizacional estratégica, são utilizadas ferramentas de gestão administrativa que simplificam o seu equacionamento e sua operacionalização, denominadas, aqui, gestão operacional. As ferramentas de gestão operacional, diferentemente das metodologias organizacionais, trazem embutidas nos seus conceitos, equações simples e de fácil aplicação. Contudo, fácil aplicação não significa que sejam aplicadas com freqüência.

Entre as metodologias de gestão operacional, tratou-se da gerência por projetos, da gerência institucional e dos indicadores de efetividade. A gerência por projetos, segundo Midler (1995), organiza as ações estratégicas de modo que sejam ampliadas as possibilidades destas serem implementadas. A gerência institucional - adaptando-se às idéias de Souto-Maior (1994) e Bertrand (1995) - tem a função de retroalimentar, de acordo com uma visão sistêmica, todos os projetos estratégicos, para que estes sejam realmente implementáveis. E os indicadores de efetividade, conforme Kaplan e Norton (1997), ajudam a organização a melhor dimensionar os seus resultados intra-organizacionais, relacionando-os com os extra-organizacionais.

\section{Planejamento para o desenvolvimento sustentável}

Para complementar e suplementar a teoria da gestão organizacional estratégica, a abordagem do planejamento para o desenvolvimento sustentável partiu das idéias de Sachs e de sua equipe de pesquisadores do Centre International de Recherche d'Environnement e Developement (CIRED).

A vertente do desenvolvimento sustentável, discutida neste trabalho, privilegia um enfoque mais abstrato, não verificado ainda na realidade factual. Essa vertente propõe uma nova ética para o desenvolvimento que se deseja para a humanidade, ou seja, um desenvolvimento socialmente mais justo, ambientalmente prudente e economicamente eficiente. Essa vertente se distancia da ótica economicista - que deseja assegurar a 
sustentabilidade do desenvolvimento societário vigente - valorizando economicamente tanto os aspectos ambientais quanto os sociais.

Sachs (1986a e 1986b) pressupõe três premissas gerais contidas num planejamento para o desenvolvimento sustentável: consideração do local e seu desenvolvimento, participação da sociedade civil no planejamento e dimensões de sustentabilidade. Dessas premissas, foram consideradas, inicialmente, as implicações do espaço e do desenvolvimento local, apontados pelo relatório Brundtland (COMISSÃO, 1991) como os verdadeiros incubadores das atividades do desenvolvimento global, já que ambos vêm interferindo, em efeito cascata, nos demais contextos que os englobam.

A receita para promover o desenvolvimento local sugere, especialmente, a prática de duas ações políticas. A primeira consiste na participação de todas as esferas da sociedade - Estado, mercado e sociedade civil - através de arranjos institucionais, considerados ações coletivas que produzem o bem-estar social. Segundo Ostrom (1990), os arranjos constroem um capital social, que pode ser entendido como resultado final da produção do bem-estar social.

A segunda ação política envolve a busca de mecanismos que assegurem investimentos locais, provenientes de boa parcela da riqueza gerada pela própria localidade, a fim de garantir o desenvolvimento local sustentado, que, então, deverá ser regulado no próprio município. Segundo Godard (1987), essa capacidade de uma sociedade adquirir um certo domínio sobre o seu desenvolvimento se chama desenvolvimento endógeno.

Para que seja alcançado o desenvolvimento sustentável, Sachs (1993) aponta cinco critérios de sustentabilidade - social, econômico, ambiental, espacial e cultural. Segundo ele, se as dimensões de sustentabilidade forem atendidas no planejamento do desenvolvimento, pode-se inferir que esse desenvolvimento é sustentável. Entretanto, o próprio autor aceita que numa época em que acontecem tantas mudanças, inclusive no campo ético, como a atual, um enfoque de planejamento pode ser considerado como estando na direção do desenvolvimento sustentável, se, pelo menos, contemplar parcialmente alguns desses critérios de sustentabilidade.

\section{Construção do modelo SiGOS}

Partindo, então, da teoria da gestão organizacional estratégica e do planejamento para o desenvolvimento sustentável, chegou-se a uma proposição preliminar do modelo SiGOS.

\section{Proposição preliminar}

A versão preliminar do modelo SiGOS apontou três etapas componentes da estrutura: a gestão organizacional estratégica, os arranjos institucionais e os indicadores de efetividade. Entretanto, a gestão organizacional estratégica foi a única etapa que conseguiu apresentar passos pedagógicos, enquanto que as outras se restringiam a descrições. No entanto, havia outra questão ainda sem reposta: qual seria a sequiência entre a primeira, a segunda e a terceira etapa?

\section{Gestão organizacional estratégica}

Essa etapa é a que operacionaliza sistematicamente o modelo de gestão. Está fundamentada em estudos teóricoempíricos sobre a etapa de implementação de estratégias da metodologia de planejamento e, principalmente, nas experiências realizadas pela Associação de Profissionais que promovem o Planejamento Estratégico e Participativo (Apep). A maioria dos autores e praticantes do planejamento estratégico - entre eles Oliveira (1988), Bryson (1989) e Nutt e Backoff (1992) - aceitam que este abrange três fases distintas:

- fase de delineamento de estratégias - que incorpora as etapas relacionadas às questões estratégicas, às ações estratégicas e aos projetos estratégicos;

- fase de análise ambiental (ambiente externo e interno); e 
- fase de execução, acompanhamento, controle e avaliação - que envolve a etapa de avaliação.

A gestão organizacional estratégica é efetivada através de seis passos:

- primeiro passo (questões estratégicas) - determina os problemas mais importantes para a organização;

- segundo passo (ambiente externo) - analisa as oportunidades e ameaças ambientais

- terceiro passo (ambiente interno) - analisa os pontos organizacionais fortes e fracos.

Através da análise ambiental (segundo e terceiro passos), é confirmada a importância das questões estratégicas, que, ao mesmo tempo, subsidiam a formulação de soluções.

- quarto passo (ações estratégicas) - determina as ações que solucionam as questões estratégicas;

- quinto passo (projetos estratégicos) - consiste no agrupamento dessas ações em projetos estratégicos;

- sexto passo (gerência institucional) - acompanha, controla e avalia os projetos estratégicos, isto é, retroalimenta todo o processo.

A figura 1 ilustra a reorganização desses passos:

Figura 1

Gestão organizacional estratégica

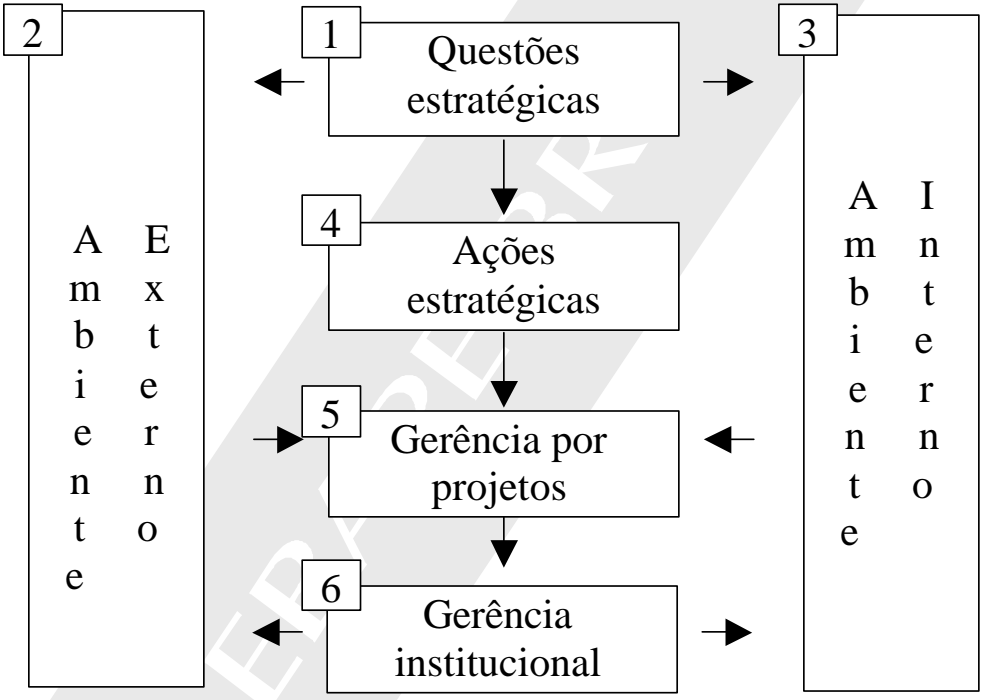

\section{"Arranjos institucionais"}

Surgiu da combinação do elemento "espaço local" com o elemento "arranjos institucionais". Segundo Dowbor (1987), Tratemberg (1987) e Gondim (1994), a etapa arranjos institucionais implica a participação de todas as organizações que representam as esferas da sociedade (Estado, mercado e sociedade civil) e que, de alguma forma, estão interessadas no desenvolvimento de um determinado local.

Esses interesses organizacionais sobre o local viabilizam os recursos necessários para implantar as ações que solucionam as questões estratégicas. Por conseqüência, asseguram a capacidade de um determinado município (entendido como um local) adquirir um certo domínio sobre o seu desenvolvimento.

\section{"Indicadores de efetividade"}

Essa etapa também resultou do entrelaçamento de dois elementos: espaço local e dimensões de sustentabilidade. Segundo adaptações de Kaplan e Norton (1997), consiste em estabelecer parâmetros para a 
ação técnica intra-organizacional (eficiência de processos e eficácia de resultados), ligada aos critérios internos organizacionais, exercida na ação técnica extra-organizacional (efetividade para o local beneficiado), mais ligada aos critérios externos organizacionais. Se os indicadores de efetividade forem alcançados, pode-se afirmar que a organização satisfaz os beneficiários de um determinado local.

Foi verificado que esses critérios externos organizacionais podem ser balizados pelas dimensões de sustentabilidade do desenvolvimento sustentável apontadas por Sachs (1993). Propôs-se, então, um conjunto de medidas de atributos de indicadores de efetividade, com base nas dimensões sociais, econômicas, ambientais, espaciais e culturais, para que a organização pudesse avaliar e reorientar os seus esforços.

\section{Proposição preliminar aperfeiçoada}

Uma vez que o modelo SiGOS deixava a desejar, partiu-se para uma nova revisão bibliográfica e para a pesquisa de experiências internacionais realizadas durante o estágio no Centre de Recherches sur le Brésil Contemporain (CRBC), na L'École des Hautes Etudes en Sciences Sociales (EHESS), em Paris. Embora não se tenha avançado como se desejava no modelo preliminar SiGOS, foi possível aperfeiçoar esse modelo. Retornando ao Brasil, convênios/parcerias foram firmados pelo pesquisador com órgãos que promovem o desenvolvimento municipal ou microrregional no estado de Santa Catarina, com o objetivo de melhorar processos de gestão já instalados em organizações e de implantar a pretensa proposta normativa do modelo SiGOS já disponível.

As experiências realizadas com a proposta preliminar do modelo SiGOS aperfeiçoado estão expostas e analisadas em relatórios técnicos. Com base nesses relatórios, serão apresentados alguns extratos dessas experiências. Segundo os relatórios técnicos (SAMPAIO, 1997a, 1997b, 1997c, 1997d, 1997e e 1998), as lições nesse período de oito meses foram muitas. Entre elas se destacam as seguintes:

- na etapa de arranjo institucional é importante deixar claro o setor de atuação da organização ou do arranjo institucional. É imprescindível contar com a participação das lideranças nos arranjos institucionais; pois nas etapas ditas "mais operacionais", os outros participantes podem se guiar sem necessidade da presença dos verdadeiros "tomadores".

A etapa arranjo institucional começa pela determinação de uma organização líder entre outras organizações que compõem o arranjo (Estado, mercado e sociedade civil). Essa mesma organização líder - ou outra que venha a liderar -, utilizando um modelo de gestão organizacional, coordenará um plano ou um conjunto de ações que formule as questões estratégicas organizacionais;

- na etapa gerência institucional é vital criar uma estrutura virtual ou física que coordene todos os projetos estratégicos, inclusive, com a possibilidade de criação de uma nova organização ou, mesmo, de um novo departamento. Após a criação dessa nova estrutura, é elaborado um plano de ação que contenha, sobretudo, ações que solucionem os problemas estratégicos a curto prazo. Aliás, essas ações a curto prazo são aquelas que oxigenam as de médio e longo prazo. Também é importante apresentar os projetos estratégicos de forma clara e sintética, inclusive, utilizando inserções publicitárias nos meios de comunicação, para a comunidade local;

- na etapa indicadores de efetividade confirmou-se que esta pode ser considerada como um termômetro organizacional para avaliar se a organização está sendo efetiva para os seus beneficiários.

\section{Proposição referencial: SiGOS}

Partindo de alguns extratos dessas experiências realizadas em Santa Catarina (SAMPAIO, 1997a, 1997b, 1997c, 1997d, 1997e e 1998), chegou-se a uma proposição referencial do modelo SiGOS. O adjetivo "referencial" é uma precaução, pois as avaliações realizadas - embora muitas delas tenham sido apontadas pelos próprios participantes dessas experiências - foram coordenadas também pelo próprio autor do modelo.

O modelo referencial SiGOS é constituído de oito etapas: 


\section{Figura 2}

Modelo referencial de gestão organizacional estratégica para o desenvolvimento sustentável (SiGOS)

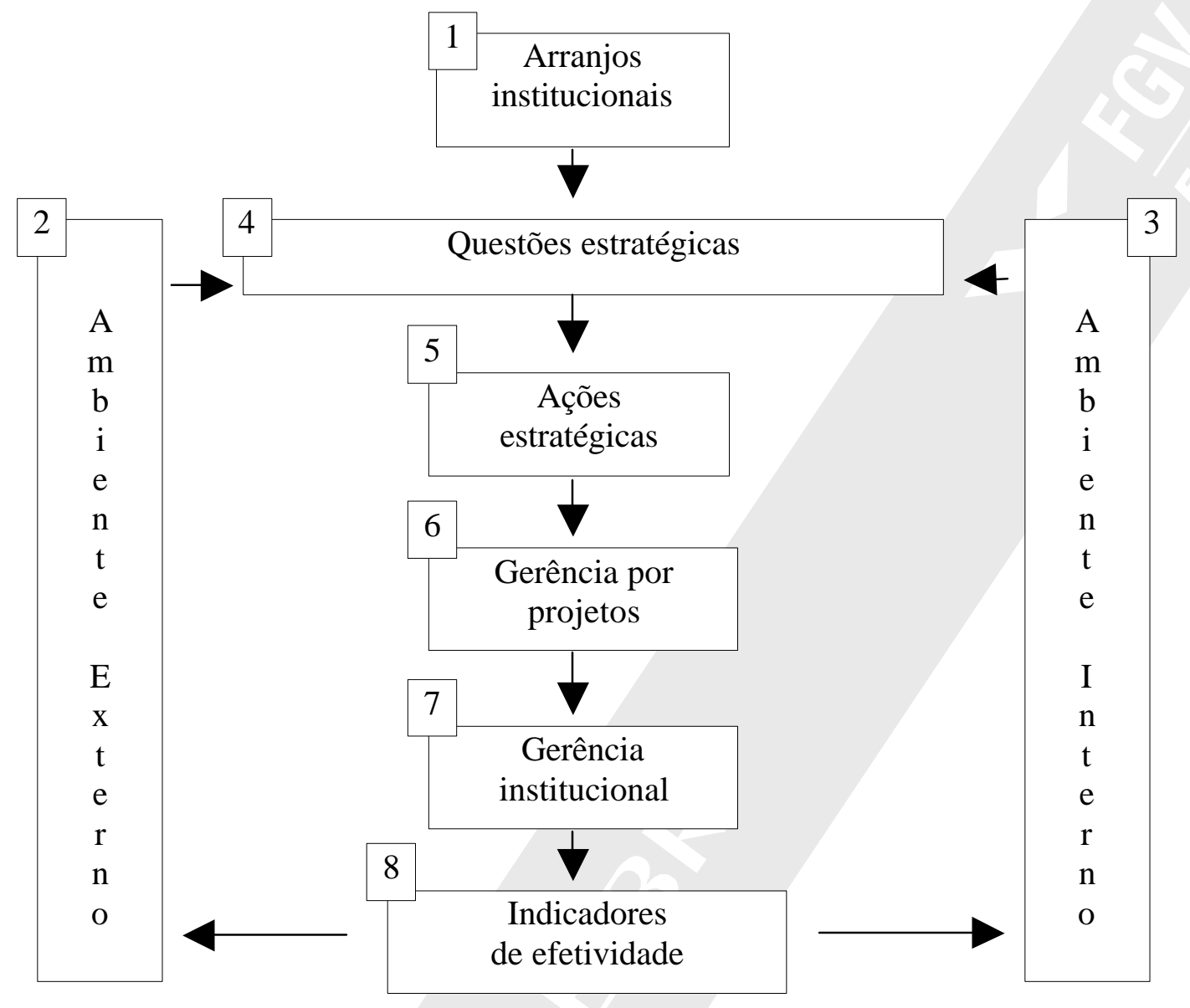

- etapa 1 - arranjos institucionais: é o conjunto de inter-relações de entidades e de normas legislativas que têm a finalidade de organizar (elaborar e implementar) planos ou ações, cujos objetivos são de interesse público. Essa etapa começa pela determinação de uma organização líder que compõe o arranjo (Estado, mercado e sociedade civil) de um determinado local;

- etapa 2 - ambiente externo: é o ambiente que influencia a organização. As influências podem se apresentar como uma oportunidade ou uma ameaça à organização;

- etapa 3 - ambiente interno: é o ambiente controlado pela organização. Esse controle pode ser caracterizado como um ponto forte ou fraco da organização;

As etapas 2 e 3 (ambientes externo e interno) compõem a análise ambiental, incorporada na maioria das metodologias de gestão organizacional, sobretudo, pela importância de se conhecer o ambiente organizacional.

- etapa 4 - questões estratégicas: consiste no levantamento dos problemas mais importantes para uma organização. Aqui subentende-se que um arranjo institucional pode ser considerado como uma organização. Caso a organização não possa agir para solucionar esses problemas, conseqüentemente, estes não poderão ser considerados como uma questão estratégica, pelo menos para essa organização (SOUTO-MAIOR, 1994).

- etapa 5 - ações estratégicas: é aquela que desenvolve as soluções viáveis das questões estratégicas. De modo geral, as ações estratégicas surgem, num primeiro momento, de técnicas do tipo brainstorming e brainwriting (SOUTO-MAIOR, 1994) que estimulam todas as soluções possíveis, 
para, então, num segundo momento, depurá-las. Uma ação bem elaborada é aquela que pode ser implantada, cuja responsabilidade de implementação deve ser atribuída a alguém de dentro da organização ou do arranjo institucional, da mesma forma que os recursos têm que estar orçados e disponíveis.

- etapa 6-gerência por projetos: ela emerge para melhor gerenciar (eliminando ações redundantes e racionalizando recursos) a quantidade e a variedade de ações estratégicas surgidas para solucionar as questões estratégicas. A gerência por projetos é uma ferramenta organizacional que se utiliza de uma estrutura matricial para implantar e monitorar sistematicamente um conjunto de ações estratégicas e seus respectivos responsáveis, ou seja, o projeto em si. Pela complexidade dessa estrutura, os projetos são muito bem detalhados, conforme ilustra o quadro a seguir:

Quadro 1

Gerência por projetos

\begin{tabular}{ll}
\hline A. título & G. ações facilitadoras \\
\hline B. objetivo & G.1 responsável \\
\hline C. justificativa & G.2 equipe de trabalho \\
\hline D. coordenador & G.3 prazos: início e término \\
\hline E. prazo total & G.4 recursos \\
\hline F. critério avaliador & G.5 critério avaliador \\
\hline F.1 meta & G.5.1 meta \\
\hline F.2 histórico da meta & H. orçamento total por fonte de recursos \\
\hline
\end{tabular}

$\mathrm{Na}$ etapa gerência por projetos, o passo que merece comentário é o critério avaliador (ou critérios avaliadores), pois é a partir dele que se vai julgar se o objetivo do projeto foi atingido ou não. Já através da meta, é que se quantifica ou qualifica o objetivo.

- etapa 7 - gerência institucional: é um conjunto de ferramentas operacionais que se utiliza de uma estrutura matricial para implantar e monitorar sistematicamente um conjunto de projetos e seus respectivos coordenadores; ou seja, o plano como um todo. A gerência institucional está dividida em quatro subetapas, observadas no quadro 2 :

Quadro 2

Gerência institucional

\begin{tabular}{ll}
\hline A. avaliação de performance & C. política de recompensa \\
\hline B. sistema de informações gerenciais (SIG) & D. plano de comunicação \\
\hline
\end{tabular}

- subetapa A - avaliação de performance: tem como objetivo avaliar os projetos e todas as suas ações facilitadoras, utilizando critérios que sugerem um indicador de performance, ou melhor, uma meta. $\mathrm{O}$ quadro seguinte apresenta os cinco componentes dessa subetapa:

Quadro 3

Avaliação por performance

\begin{tabular}{lll}
\hline A. preparação & C. coleta de dados & E. tomada de decisão \\
\hline B. revisão de metas & D. relatórios & \\
\hline
\end{tabular}

A preparação sugere que a organização tem que desenvolver equipes de medição e criar um clima adequado para a avaliação da performance. A revisão de metas avalia e reescreve os critérios avaliadores e metas do projeto estratégico, bem como do seu conjunto de ações facilitadoras, baseando-se na negociação entre avaliadores e avaliados. A coleta de dados seleciona e busca dados para medição, enquanto os relatórios geram 
a informação desejada. Finalmente, são tomadas as decisões baseadas em todo o processo de avaliação de performance.

- subetapa B - sistema de informações gerenciais (SIG): tem a finalidade de organizar (automaticamente ou manualmente) todos os dados de um determinado sistema, transformando, numa primeira etapa, dados em informações operacionais e, numa segunda etapa, informações operacionais e gerenciais. Essa subetapa compreende três elementos demonstrados no quadro seguinte:

\section{Quadro 4}

Sistema de informações gerenciais (SIG)

\begin{tabular}{lll}
\hline A. dados & B. processamento & C. informação \\
\hline
\end{tabular}

Os dados constituem a matéria-prima de um processo informativo e o processamento é a operação manual ou computadorizada que transforma dados em informação. A informação é o conjunto de dados ordenados racionalmente, que levam à tomada de decisão.

- subetapa C - política de recompensa: tem a finalidade de estimular e motivar os coordenadores, os responsáveis e a equipe de trabalho dos projetos, de modo que as metas possam ser atingidas. Essa subetapa é composta por quatro elementos apresentados no quadro seguinte:

Quadro 5

Política de recompensa

\begin{tabular}{ll}
\hline 1. preparação & 3. pontuação \\
\hline 2. metas & 4. recompensa \\
\hline
\end{tabular}

A preparação implanta a motivação como filosofia de trabalho na organização, inclusive diagnosticando as variáveis motivacionais. As metas são estabelecidas pelo projeto e pelas ações facilitadoras, oriundas da subetapa de avaliação de performance. A pontuação é um sistema que classifica as ações realizadas segundo os resultados alcançados, enquanto que a recompensa é a forma pela qual a organização retribuirá os esforços despendidos no alcance dos resultados.

- subetapa D - plano de comunicação: delineia e direciona as estratégias de comunicação de uma organização, considerando as singularidades do comunicador, da mensagem do comunicador, do canal de comunicação e do receptor. Essa subetapa é formada por cinco elementos apresentados no seguinte quadro:

Quadro 6

Plano de comunicação

\begin{tabular}{ll}
\hline 1. instituição & 4. canais de comunicação \\
\hline 2. opinião pública & 5. avaliação \\
\hline 3. mensagem & \\
\hline
\end{tabular}

A instituição identifica as estruturas de valores legais, éticos, sociais e de negócios de uma organização. A opinião pública tem que ser considerada como o mercado potencial de consumo da instituição. A mensagem é a informação que se deseja transmitir para a opinião pública. Os canais de comunicação são os meios pelos quais uma instituição veicula as suas mensagens para a opinião pública, e a avaliação é o processo contínuo que atualiza o plano de comunicação institucional.

- etapa 8 - indicadores de efetividade: ela também constitui uma ferramenta operacional que utiliza critérios de efetividade de uma organização para com o seu público; isto é, verifica se a organização contribui para o bem-estar da população, conforme ilustra o quadro 7. 
Quadro 7

Indicadores de efetividade

\begin{tabular}{llll}
\hline A. número & C. medidas & D. relação comparativa & E. fórmula \\
\hline B. indicadores & C.1 valor & D.1 valor \\
\hline & C.2 medição & D.2 medição \\
\hline & C.3 período & D.3 período & \\
\hline & C.4 fonte & D.4 fonte \\
\hline
\end{tabular}

Depois de estabelecidos pela própria organização, esses indicadores impõem parâmetros para a eficiência dos seus processos, bem como para a eficácia dos resultados alcançados, num processo de feedback organizacional. Para demonstrar graficamente o conjunto de indicadores de efetividade, é sugerida a representação em polígono regular, conforme o exemplo da figura 3. Adaptando as idéias de Kaplan e Norton (1997), o polígono regular é formado pelo conjunto de indicadores determinado pela organização para aferir a efetividade do projeto. Nesse exemplo, são apresentados oito indicadores. No extremo de cada linha é indicada a meta desejada para o indicador. Os resultados alcançados são comparados com a meta desejada e indicados por percentual. O resultado alcançado no indicador 4 foi de $100 \%$ sobre a meta desejada. Depois que todos os resultados alcançados são marcados no polígono, surge a figura de um segundo polígono. No exemplo, o polígono que surge é irregular, pois nem todos os resultados alcançados obtiveram $100 \%$ do desejado.

Figura 3

Polígono representando os indicadores de efetividade

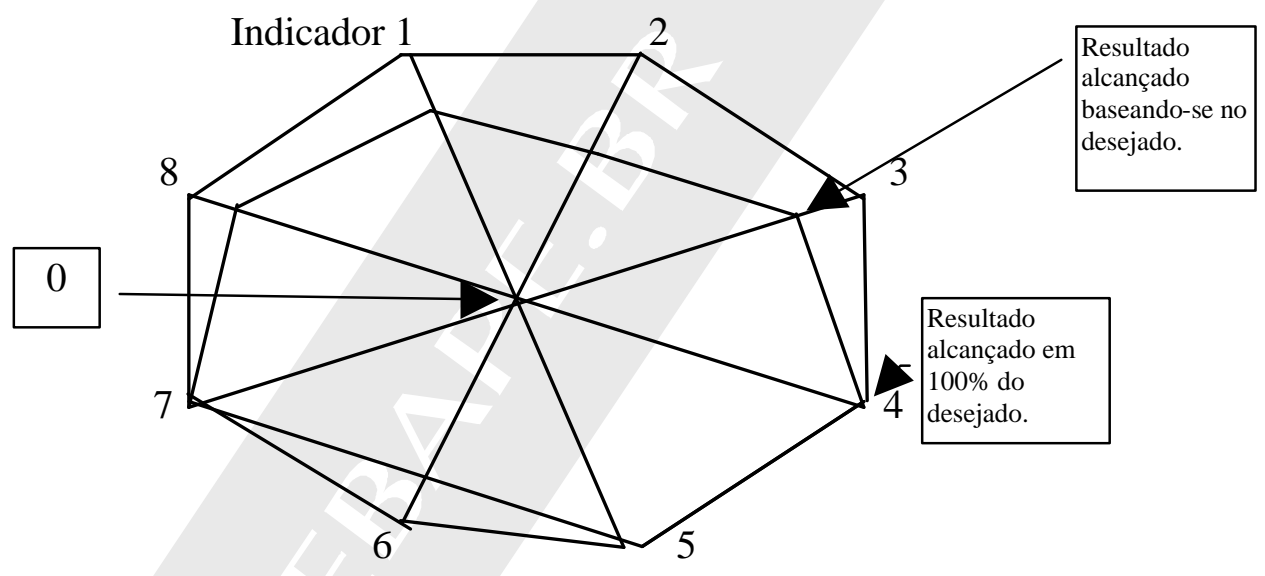

Pontos processuais positivos e negativos dos três estudos de casos.

O modelo referencial SiGOS foi revisto a partir da confrontação de três estudos de casos: Centro de Estudos e Pesquisas Ambientais (Cepa), implantado pela unidade da Alcoa de Poços de Caldas-MG; Projeto Integração Infância Adolescência (PIÁ Ambiental), coordenado pela Secretaria Municipal de Meio Ambiente de Curitiba-PR (SMMA) e o Projeto Empresas Comunitárias, iniciado pela Associação Comercial e Industrial de Toledo-PR (Acit). Partindo dos quatro eixos norteadores - arranjo institucional, gestão organizacional, espaço local e indicadores de sustentabilidade -, os projetos revelaram importantes pontos processuais, tanto positivos quanto negativos:

- as lideranças das organizações (ou as pessoas líderes) que iniciaram os projetos, ocuparam os papéis de animadores sociais, cuja função principal foi oxigenar a gestão dos arranjos institucionais. Mesmo que tenha ocorrido algum favorecimento para as organizações que lideraram os projetos, isso não descaracteriza um arranjo institucional. O que, talvez, poderá descaracterizar um arranjo é se dele não surgirem resultados que beneficiem a comunidade ou a sociedade como um todo. Embora possa parecer contraditório, a restrição de se ter apenas uma organização ou uma liderança na condução do arranjo implica uma certa tendenciosidade 
de opiniões e idéias, independentemente da intenção ser boa ou não. Essa tendência poderá distorcer a ação política, entendida como processo de negociação da diversidade de interesses organizacionais, e, conseqüentemente, limitar o capital social apontado por Ostrom (1990), ambos inseridos no contexto de um arranjo institucional;

- a gestão organizacional pode ser conduzida através de um planejamento, de uma liderança organizacional, por pensamento estratégico, ou ainda pelas combinações possíveis dessas metodologias. Também foi constatado que o plano de comunicação foi uma etapa imprescindível para divulgar os projetos. Por outro lado, as etapas que incluem a gestão operacional (com exceção do plano de comunicação), quando utilizadas, foram pouco exploradas, sobretudo a avaliação de performance e o sistema de informações gerenciais. Essas etapas, quando implementadas, retroalimentam o sistema proposto pelo modelo. Em relação ao plano de comunicação, nada impede que projetos mal gerenciados ou, até mesmo, malintencionados acabem divulgando apenas resultados mais convenientes para se firmar uma boa imagem institucional de uma organização, isto é: a visão econômica sobrepujando a visão ética do desenvolvimento sustentável;

- ao mesmo tempo em que apresentaram benefícios efetivos para uma faixa ou para toda a população do município, os projetos possibilitaram, de forma encadeada, que outras faixas ou outros municípios também fossem beneficiados. Nesse sentido, espera-se que um resultado não efetivo para uma população não se propague da mesma forma para os municípios vizinhos;

- mesmo havendo a dificuldade de se revelar indicadores criteriosos, é importante considerar os indícios que possibilitam identificar se um projeto é efetivo ou não. Embora pareça contraditório a essa possibilidade de indícios, o caráter interdisciplinar de um atributo e o descaso por critérios rigorosos de indicadores de sustentabilidade são motivos suficientes para questionar a validade desses indícios que apontam a efetividade do projeto, independentemente da intenção ser boa ou não.

\section{Conclusão}

Os pontos processuais positivos e negativos apontados no estudo de casos foram incorporados ao modelo normativo consolidado SiGOS.

O modelo SiGOS versão 1999 está representado graficamente igual ao modelo SiGOS referencial, conforme demonstrado na figura 2. Entretanto, ambos se distinguem basicamente nos cuidados que devem ser considerados na condução de algumas etapas:

\section{Etapa 1 - arranjo institucional}

Mesmo que se prefira ter um arranjo institucional liderado por uma organização - que pode resultar num direcionamento tendencioso na condução do arranjo - do que não se ter nenhum arranjo institucionalizado, sabe-se das possíveis fragilidades do capital social produzido. Esse problema é acentuado, principalmente, levando em conta que o próprio arranjo institucional já é um resultado. Numa analogia com as idéias de Banfield (1962), os meios são tão importantes quanto os fins. Portanto, o capital social produzido, decorrente de um arranjo institucional conduzido apenas por uma liderança organizacional, pode privilegiar interesses que contrariem a visão ética do desenvolvimento sustentável.

A visão ética do desenvolvimento sustentável sugere mudanças quanto à racionalidade econômica do atual tipo de desenvolvimento. Não se deseja que a dimensão econômica supere as dimensões social e ambiental do desenvolvimento, nem vice-versa, e sim que o desenvolvimento humano incorpore essas três dimensões. Também não se quer mais que o mercado, o Estado e a sociedade civil sejam esferas de poder caracterizadas apenas por suas distinções no espaço político, ou somente por suas semelhanças; mas que, como entende Friedmann (1992), a unidade da sociedade seja estabelecida em sua diversidade.

Entretanto, também são conhecidas as fissuras institucionais produzidas pela ótica economicista do desenvolvimento. Essas fissuras são ações produzidas, sem necessariamente serem previstas, à margem de 
ações voltadas ao sucesso e, às vezes, também chamadas infelizmente de estratégicas, materializadas em sujeitos oportunistas para influenciar outros. Essas fissuras institucionais surgem mais freqüentemente a partir do esgotamento do paradigma econômico vigente, que não mais explica a maior parte dos fenômenos observados e nem permite soluções para os problemas que a maioria das pessoas quer resolver. Emergem, assim, novos paradigmas, como é a visão ética do desenvolvimento sustentável.

\section{Etapas 2 e 3 - análise ambiental; 4 - questões estratégicas e 5 - ações estratégicas. Essas etapas compõem a gestão organizacional estratégica.}

Fazendo uma analogia, sem grande rigor, entre organização e máquina, a gestão organizacional estratégica é o motor que faz funcionar essa máquina. Não se trata do motor físico mas, sim, de sua função. O motor pode ser melhorado, substituindo componentes mecânicos por elétricos ou, ainda, por circuitos eletrônicos microminiaturizados, os chips. Embora não se negue os valores agregados contidos nas novas tecnologias, a função principal do motor continua a mesma, ou seja, fazer funcionar a máquina.

Voltando ao âmbito organizacional, isso implica que muitas metodologias organizacionais, às vezes enaltecidas até como revolucionárias, contêm os mesmos pressupostos, isto é, fazer funcionar as organizações. Aqui, não está sendo proposto nenhum tipo específico de metodologia de gestão, mas é sugerido apenas que a metodologia utilizada seja tecnicamente dominada pela organização líder (ou organizações líderes), como foi demonstrado no estudo de casos.

\section{Etapas 6 - gerência por projetos e 7 - gerência institucional: etapas que compõem a gestão operacional.}

Utilizando-se da mesma analogia entre organização e máquina, a gestão operacional equivale a cada uma das subfunções que têm como principal função, fazer funcionar o motor. Portanto, a gestão operacional é aquela que faz funcionar a gestão organizacional. Cada gestão operacional é detalhada metodicamente em passos. A metódica dos passos, embora pareça resultar na homogeneização das idéias, favorece o surgimento de idéias heterogêneas por facilitar a ação de pensar.

A gerência por projetos tem o objetivo de reorganizar as ações estratégicas para que estas se mostrem implementáveis. A gerência por projetos estimula a eficiência na racionalização dos esforços da organização para produzir soluções para as questões estratégicas.

A gerência institucional tem a função de retroalimentar todos os projetos estratégicos para que estes sejam realmente implementáveis. Nesse sentido, é necessário que as subetapas da gerência institucional - avaliação de performance, sistema de informações gerenciais, política de recompensa e plano de comunicação - sejam implementadas na sua íntegra, pois são elas que retroalimentam o sistema processual formado pelo modelo SiGOS. A retroalimentação, ao contrário da avaliação, tenta conduzir os projetos aproveitando-se dos acertos e erros ocorridos para que as ações elaboradas, além de implementadas, tenham resultados eficazes.

\section{Etapa 8 - indicadores de efetividade.}

Os indicadores de efetividade, também incorporando a gerência operacional, pressupõem uma ação técnica extra-organizacional, isto é: consiste no esforço da organização de ser efetiva para os seus beneficiários. Geralmente, outros modelos enfatizam a ação técnica intra-organizacional, eficiência de processos e eficácia dos resultados, típica nos modelos de gestão administrativa. A grande contribuição do modelo SiGOS é que a ação técnica extra-organizacional - aliás, direcionada para a ótica ética do desenvolvimento sustentável, como defendido neste trabalho -, conduz a ação intra-organizacional, e não o inverso, como faz a ótica economicista.

Neste estudo não se tem a pretensão de considerar o modelo SiGOS-versão 1999 como acabado. Já que se trata de um modelo flexível, a expectativa é a de que complemente outras abordagens, mesmo porque surgiu exatamente dessas abordagens. A modéstia também se justifica por um paradoxo que o transforma numa metodologia eternamente inacabada. Por um lado, é um modelo incipiente com limitações que, ao longo de muitas experimentações empíricas, vai se consolidando como uma abordagem mais lapidada. De outro, possui uma característica de adaptabilidade, originada, sobretudo, no processo participativo sugerido em suas etapas. 


\section{Referências bibliográficas}

BANFIELD, E. C. End and means in planning. International Science Journal, v.11, n.3., p.361-368, 1962.

BERTRAND, A. (Coord.). Vers la gestion locale communautaire des ressources renouvelables: propositions d'une politique de décentralisation de la gestion des ressources renouvelables. Paris: Ministére Français de la Coopération, 1995.

BRYSON, J. M. An effective strategic planning approach for public and nonprofit organizations: a guide to strengthening and sustaining organizational achievement. London: Jossey-Bass, 1989.

COMISSÃO MUNDIAL SOBRE MEIO AM BIENTE E DESENVOLVIM ENTO. Nosso futuro comum. Rio de Janeiro: FGV, 1991.

DOWBOR, L. Introdução ao planejamento municipal. São Paulo: Brasiliense, 1987.

FRIEDM ANN, J. Empowerment. Cambridge: Blackwell, 1992.

GODARD, 0. et al. Desarrollo endogeno y diferenciacion de espacios de desarrollo: um esquema de analisis para el desarrollo local. Estudios Territoriales, n.24, p.135-147, 1987.

GONDIM, Linda. A moral e a política dos outros: algumas reflexões sobre cidadania e corrupção no Brasil. Cadernos de Ciências Sociais. Fortaleza: UFC/NEPS, n.25, 1994.

KAPLAN, R. S.; NORTON, D. P. A estratégia em ação: balanced scorecard. Rio de Janeiro: Campus, 1997.

MIDLER, C. Une affaire d'apprentissage collectif. L'Expansion Management Review, n.76, mars 1995.

NUTT, P. C.; BACKOFF, R. W. Strategic management of public and third sector organizations. San Francisco: Jossey- Bass Pub., 1992.

OLIVEIRA, D. P. R. Planejamento estratégico: conceitos, metodologia e prática. São Paulo: Atlas, 1988.

OSTROM, E. Governing the commons - the evolution of institutions for collective action. Cambridge: University Press, 1990.

SACHS, I. Ecodesenvolvimento: crescer sem destruir. São Paulo: Vértice, 1986a.

Espaços, tempos e estratégias do desenvolvimento. São Paulo: Vértice, 1986b.

Estratégias de transição para o século XXI: desenvolvimento e meio ambiente. Studio Bobel: Fundap 1993.

SAMPAIO, C. A. C. Planejamento estratégico participativo e gestão de projetos estratégicos para a modernização da associação dos municípios do meio- oeste catarinense (Ammoc). Joaçaba: Ammoc, 1997a.

Planejamento estratégico participativo e gestão de projetos estratégicos para a modernização da associação dos municípios do extremo sul catarinense (Amesc). Araranguá: Amesc, 1997b.

Planejamento estratégico participativo e gestão de projetos estratégicos para a modernização da federação catarinense de municípios (Fecam). Florianópolis: Fecam e SDM, 1997c.

Curso de gestão estratégica de arranjos institucionais para o desenvolvimento sustentável. Florianópolis: Cepagro, 19̄9 $\overline{\text { d. }}$ Mimeografado.

SAMPAIO, Carlos Alberto Cioce. Planejamento e gestão organizacional para a associação de municípios do extremo sul catarinense (AMESC). Araranguá: Associação de Municípios do Extremo Sul Catarinense. Relatório. 1997e.

$\overline{19} \overline{9} \overline{8}$

Planejamento estratégico participativo na associação dos municípios da região serrana (Amures). Lages: Amures,

Uma proposta de um modelo de gestão organizacional estratégica para o desenvolvimento sustentável (SiGOS). 1999. Tese (Doutorado em Engenharia de Produção) - Centro Tecnológico, Universidade Federal de Santa Catarina.

SOUTO-MAIOR, J. Planejamento estratégico participativo: uma abordagem para o setor público. In: ENCONTRO ANUAL DA ANPAD 18., Curitiba, 1994. Anais... Curitiba: ANPAD, v.3, p.57-74, 1994.

TRATEMBERG, M. Uma prática de participação nas coletivizações na Espanha (1936-1939). Participação e participações, São Paulo: Babel Cultural, 1987. 